\title{
Cost-Effectiveness of Asthma Step-Up Therapy as an Increased Dose of Extrafine-Particle Inhaled Corticosteroid or Add-On Long-Acting Beta ${ }_{2}$-Agonist
}

\author{
Nicolas Roche $\cdot$ Gene Colice $\cdot$ Elliot Israel $\cdot$ Richard J. Martin • Paul M. Dorinsky • \\ Dirkje S. Postma · Theresa W. Guilbert · Jonathan Grigg • Willem M. C. van \\ Aalderen · Francesca Barion · Elizabeth V. Hillyer · Victoria Thomas • \\ Anne Burden · R. Brett McQueen · David B. Price (iD
}

Received: January 25, 2016/ Published online: March 21, 2016

(c) The Author(s) 2016. This article is published with open access at Springerlink.com

\begin{abstract}
Introduction: Data from different healthcare systems on relative cost-effectiveness of asthma step-up therapy strategies are required to inform decision-makers and clinicians. Our objective was to compare cost-effectiveness from the United Kingdom National Health
\end{abstract}

Enhanced Content To view enhance content for this article go to www.medengine.com/Redeem/3A44F0606 1537 FB7.

Electronic supplementary material The online version of this article (doi:10.1007/s41030-016-0014-2) contains supplementary material, which is available to authorized users.

N. Roche

Respiratory and Intensive Care Medicine, Cochin Hospital Group, AP-HP, University of Paris Descartes (EA2511), Paris, France

G. Colice

Pulmonary, Critical Care and Respiratory Services,

Washington Hospital Center and George

Washington University School of Medicine,

Washington, DC, USA

Present Address:

G. Colice

AstraZeneca, Gaithersburg, MD, USA

E. Israel

Pulmonary and Critical Care Division, Brigham and Women's Hospital and Harvard Medical School,

Boston, MA, USA
Service perspective of three step-up strategies for patients with asthma uncontrolled by inhaled corticosteroid (ICS) monotherapy.

Methods: This was a historical matched cohort cost-effectiveness analysis of anonymized medical records for patients with asthma of age 12-80 years. We conducted two-way comparisons of step-up therapy using increased dose ( $\geq 50 \%)$ of extrafine-particle ICS or add-on long-acting $\beta_{2}$-agonist (LABA) via fixed-dose combination (FDC) ICS/LABA inhaler or via separate inhaler. The incremental cost-effectiveness ratio (ICER) was calculated using asthma-related direct costs

\section{R. J. Martin}

Department of Medicine, National Jewish Health, University of Colorado Denver, Denver, CO, USA

P. M. Dorinsky

Cipla Europe NV, Antwerp, Belgium

D. S. Postma

University of Groningen, Department of Pulmonary

Medicine and Tuberculosis, University Medical

Center Groningen, Groningen, The Netherlands

T. W. Guilbert

Cincinnati Children's Hospital and Medical Center, Cincinnati, $\mathrm{OH}, \mathrm{USA}$ 
during one outcome year and a composite measure of risk-domain asthma control (no asthma-related hospital attendance, acute oral corticosteroids, or consultation for lower respiratory tract infection).

Results: Patients prescribed ICS dose step-up $(n=3036) \quad$ had significantly lower baseline-adjusted, mean asthma-related healthcare costs during the outcome year than those prescribed FDC ICS/LABA $(n=3036$; mean difference, $£ 124 /$ year). ICS dose step-up had $56 \%$ probability of being less costly and marginally less effective (a trade-off), with ICER of $£ 51,449$ per additional patient controlled with FDC; and ICS dose step-up had 44\% probability of being the preferred treatment strategy (less costly and more effective). In a second comparison, ICS step-up $(n=3232)$ had $100 \%$ probability of being cheaper and more effective than adding LABA to ICS via separate inhalers $(n=6464)$.

Conclusion: For asthma step-up therapy, increasing ICS dose using extrafine-particle ICS is significantly less costly from the payer perspective and marginally (non-significantly) less effective than FDC ICS/LABA therapy containing standard fine-particle ICS. These findings apply primarily to the UK healthcare system but warrant consideration when

J. Grigg

Blizard Institute, Queen Mary University of London, London, UK

W. M. C. van Aalderen

Department of Pediatric Respiratory Medicine and Allergy, Emma Children's Hospital AMC,

Amsterdam, The Netherlands

F. Barion - E. V. Hillyer - V. Thomas · A. Burden .

R. Brett McQueen - D. B. Price

Research in Real-Life, Ltd, Cambridge, UK

D. B. Price $(\bowtie)$

Academic Primary Care, Division of Applied Health Sciences, University of Aberdeen, Aberdeen, UK e-mail: dprice@rirl.org developing guidelines in settings with strong economic constraints.

Trial Registration: ClinicalTrials.gov identifier: NCT01697722.

Funding: Teva Pharmaceuticals Limited, Petach Tikva, Israel.

Keywords: Asthma; Beclomethasone dipropionate hydrofluoroalkane; Budesonide/ formoterol fumarate dehydrate; Costeffectiveness; Extrafine-particle inhaled corticosteroid; Fixed-dose combination; Fluticasone propionate/salmeterol xinafoate; Long-acting $\beta_{2}$-agonist

\section{INTRODUCTION}

An estimated 334 million people worldwide have asthma, including 5.4 million people in the United Kingdom (UK) on current asthma therapy $[1,2]$. Asthma is an important cause of healthcare resource utilization and health-related quality of life impairment [3]. The treatment of asthma is expensive, costing the UK National Health Service (NHS) an estimated $£ 1$ billion per year in direct costs, mostly attributable to the cost of prescription medications and hospital admissions [2, 4]. Healthcare resource use and the direct costs of asthma are highest for patients with suboptimal asthma control [5-7]. Considering these costs, it is of utmost importance to generate real-life cost-effectiveness data to help decision-makers and clinicians in their decisions regarding the choice between available treatment options.

The goal of asthma therapy is to achieve the two facets of asthma control, namely, current symptomatic control and minimized risk of future acute exacerbations, which can be life threatening [3]. Asthma therapy is prescribed using a stepwise approach, beginning with 
short-acting bronchodilator (reliever medication, such as short-acting $\beta_{2}$-agonist [SABA]) at step 1 and progressing, as needed, to controller or maintenance therapy at step 2 with an anti-inflammatory medication, such as an inhaled corticosteroid (ICS). For patients receiving ICS monotherapy whose asthma remains uncontrolled, asthma management guidelines then recommend at step 3 the addition of a long-acting bronchodilator (e.g., long-acting $\beta_{2}$-agonist [LABA]), with secondary (less-preferred) options of increasing the ICS dose or adding a leukotriene receptor antagonist (LTRA) [3, 8].

These recommendations are based on the results of randomized controlled trials (RCTs) $[3,8]$; however, RCT results have limited generalizability to actual clinical practice. By one estimate up to $95 \%$ of patients with asthma would not be eligible for RCTs because of restrictive RCT eligibility criteria, such as the exclusion of smokers or obese patients [9]. Moreover, adherence to therapy and inhaler device technique are better in RCTs than among patients in clinical practice $[10,11]$. Relevantly for the step-up comparisons between increasing ICS dose and add-on LABA, most RCTs require enrolled patients to demonstrate substantial reversibility of airflow obstruction to a SABA, thereby selecting for bronchodilator responsiveness and excluding the estimated $70 \%$ of patients with asthma who fail to demonstrate sufficient bronchodilator reversibility at any given point in time [9].

Cost-effectiveness analyses of asthma therapies are usually based on economic models drawing on data from RCTs of 12-16 weeks' duration [12-15]. However, long-term clinical practice data may be more directly relevant to inform economic decisions regarding treatment choices for asthma, and effectiveness parameters such as annual exacerbation rates may be more appropriate for making treatment decisions $[16,17]$. In addition, most economic models relied on RCTs in which standard fine-particle ICS were administered, namely, ICS with particles of median mass aerodynamic diameter (MMAD) of $>2-5 \mu \mathrm{m}$. Instead, the newer extrafine-particle ICS (MMAD, $\sim 1 \mu \mathrm{m}$ ) may better treat the small airways, where inflammation is often present in asthma, and thus may be more effective than fine-particle ICS, at least for patients with small airway involvement [18, 19].

In a prior historical matched cohort study comparing step-up alternatives for patients with asthma treated in community settings [20], we found that increasing the ICS dose was as effective in controlling exacerbations over the subsequent year as adding a LABA by fixed-dose combination (FDC) ICS/LABA inhaler. The objective of the present historical matched cohort cost-effectiveness analysis was to compare direct asthma-related healthcare costs and cost-effectiveness from the UK NHS perspective of three common step-up options for asthma: increased dose of extrafine-particle ICS, add-on LABA by FDC ICS/LABA inhaler, and add-on LABA by separate inhaler. Our hypothesis was that increasing the dose of an extrafine-particle ICS would be a cost-effective alternative to therapy with ICS plus LABA in combination or separate inhalers for adults with evidence of persistent asthma. Additionally, we hypothesized that FDC ICS/LABA inhalers would be more cost-effective than separate ICS/LABA inhalers.

\section{METHODS}

\section{Data Sources and Patients}

The anonymized patient data for this matched cohort study were drawn from two UK primary 
care electronic datasets used extensively for pharmacoepidemiologic research and described in detail in prior publications: the General Practice Research Database (GPRD), now part of the Clinical Practice Research Datalink, and the Optimum Patient Care Research Database (OPCRD) [21-24]. Approval was given for use of the GPRD data by the GPRD Independent Scientific Advisory Committee. The OPCRD has been approved by Trent Multi Centre Research Ethics Committee for clinical research use, and the study protocol was approved by ADEPT (Anonymised Data Ethics Protocols and Transparency Committee), OPC's independent scientific advisory committee. Informed patient consent was neither required nor possible to obtain for this non-interventional study using anonymized data. The study was conducted according to standards recommended for observational research (further details in the supplementary material) [25].

The study period ran from January 1997 through January 2011. We included patients with asthma and no other chronic respiratory disease who were $12-80$ years old. We excluded active smokers who were $61-80$ years old because undiagnosed or comorbid chronic obstructive pulmonary disease is more likely in this older age group than in younger patients $[3,8]$. Additional inclusion criteria were ICS monotherapy for asthma during one baseline year; a step up in asthma therapy as one of the three options described below; and 2 years of continuous records in the GPRD or the OPCRD, including one baseline year before and one outcome year after the step-up date (defined as the index date). The three step-up options were as follows:

(1) Extrafine ICS step-up: an increase in ICS dose of $\geq 50 \%$ as an extrafine-particle ICS (beclomethasone dipropionate hydrofluoroalkane [HFA]; Qvar ${ }^{\circledR}$, Teva Pharmaceutical Industries Ltd., Petach
Tikva, Israel), by pressurized metered-dose inhaler (pMDI) or breath-actuated pMDI (BAI)

(2) FDC ICS/LABA: addition of LABA (with no change in ICS dose) using a fixed-dose ICS/ LABA combination of either fluticasone propionate/salmeterol xinafoate (Seretide ${ }^{\circledR}$, GlaxoSmithKline, Middlesex, UK), or budesonide/formoterol fumarate dihydrate $\quad\left(\right.$ Symbicort $^{\circledR}, \quad$ AstraZeneca, London, UK); or

(3) Separate ICS + LABA: addition of LABA by separate pMDI or BAI, with no change in ICS drug, dose, or inhaler.

\section{Resource Use and Costs}

Information on asthma-related resource use was extracted from the databases. We calculated total asthma-related direct costs in 2011 sterling (£) from the UK NHS perspective using unit costs obtained from UK national data sources [26-28], summarized in supplementary Table S1, with further details in the supplemental Methods section in the supplementary material.

\section{Effectiveness Measure}

We used a composite database measure for risk-domain asthma control as the effectiveness measure, as reported in previous publications [20, 29-31], defining asthma control as including all of the following: (1) no asthma-related hospital attendance or admission, emergency department (ED) attendance, out-of-hours attendance, or outpatient hospital attendance; and (2) no prescription for an acute course of oral corticosteroids [32]; and (3) no primary care consultation for lower respiratory tract infection [33, 34]. 


\section{Statistical Analyses}

We conducted matched cohort analyses, using two-way matching for the three cohorts, to compare outcomes for age- and sex-matched patients with similar asthma severity and baseline asthma control. Patients were matched sequentially on sex, age, the last ICS daily dose prescribed before the index date, asthma control status, mean daily dose of SABA, and the number of primary care consultations for asthma with no oral corticosteroid prescription (details in the supplementary material). Effectiveness and asthma-related costs were compared by two-way comparisons between (1) the ICS step-up cohort versus the FDC ICS/LABA cohort (comparison 1); (2) the ICS step-up cohort versus the separate ICS + LABA cohort (comparison 2); and (3) the separate ICS + LABA cohort versus the FDC ICS/ LABA cohort (comparison 3).

The costs of treatments were compared via the differences in mean asthma-related healthcare costs per patient per year during the outcome period, both unadjusted and adjusted for potential confounders (Table S2 in the supplementary material). Two-way comparisons of summary costs between matched cohorts were carried out using conditional logistic regression. Generalized linear models with a log link and gamma distribution were used to estimate adjusted mean asthma-related healthcare costs per year during the outcome period. Differences in adjusted mean costs are reported with 95\% confidence intervals (CIs) found by bootstrapping methods, using 1000 random samples taken, with replacement, from the dataset [35].

The effectiveness of treatments for matched cohorts was compared via the difference in the proportion of patients with asthma control during the outcome year, both unadjusted and adjusted for potential confounders. Adjusted proportions were estimated using generalized linear models with a logit link and binomial distribution. Proportions and differences in proportions of patients with asthma control were reported with 95\% CIs found by bootstrapping methods, using the 1000 random samples taken, with replacement, from the dataset.

The two-way differences in total asthma-related costs and proportions of patients with asthma control for the 1000 random samples were displayed graphically on cost-effectiveness planes. When the point estimates for differences in costs and effectiveness indicated a trade-off between treatments (Fig. 1, quadrants I and III), we calculated an incremental cost-effectiveness ratio (ICER) as the ratio of the difference in total asthma-related healthcare costs per patient per year (namely, the incremental cost) to the difference in proportions of patients with asthma control (namely, the incremental gain in effectiveness). When all the replicated data were in one quadrant of the cost-effectiveness plane, the ICER was reported with a 95\% CI found by bootstrapping methods. When replicated data covered more than one quadrant, we produced a cost-effectiveness acceptability curve (CEAC) in conjunction with the ICER [36-38].

\section{RESULTS}

\section{Patients}

We identified 5492, 9207, and 20,657 eligible patients who were prescribed extrafine-particle ICS dose step-up, add-on LABA by FDC ICS/ LABA inhaler, and add-on LABA to ICS by separate LABA inhaler, respectively. The 


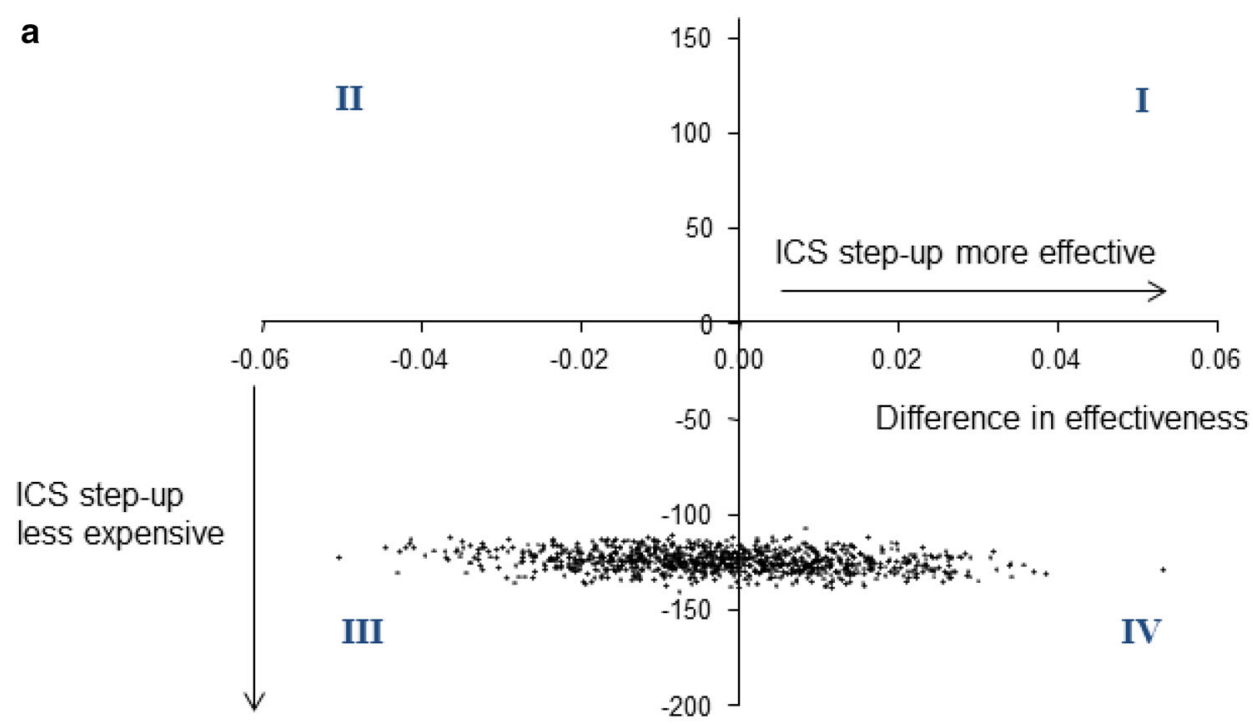

Difference in cost (£)

b

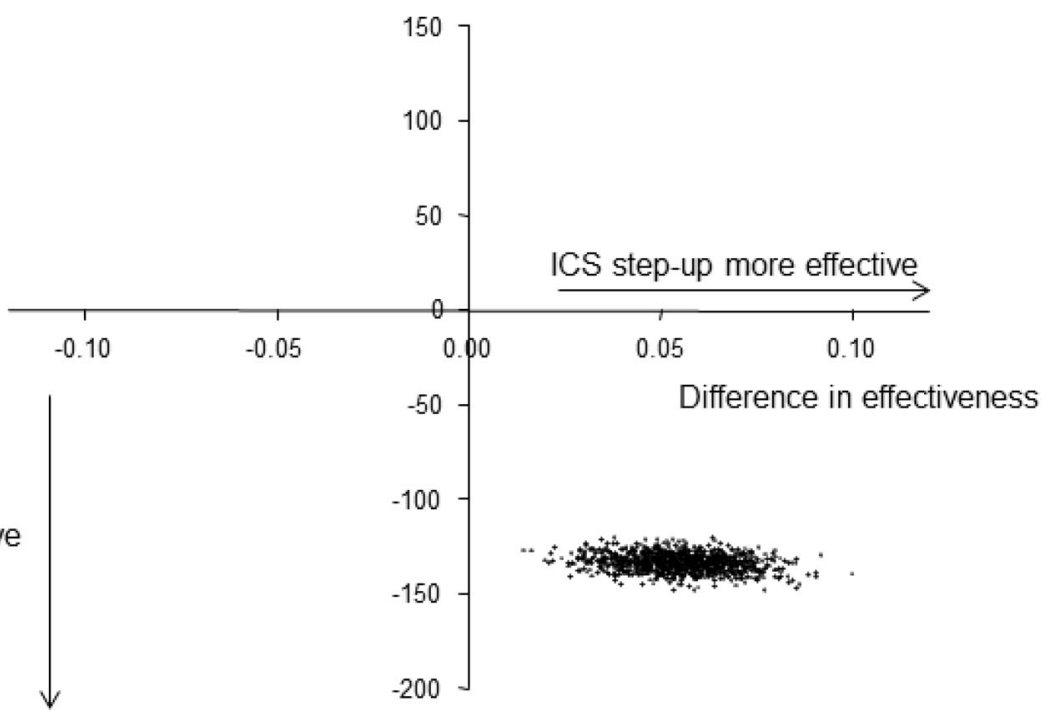

Difference in cost $(£)$

Fig. 1 Cost-effectiveness planes showing the spread of the estimated differences in cost and effectiveness, based on 1000 replicated samples, between a the ICS step-up cohort and the FDC ICS/LABA cohort and $\mathbf{b}$ the ICS step-up cohort and the separate ICS + LABA cohort. Depending where the data points lie, the four quadrants of the cost-effectiveness plane would depict the results of a step-up in asthma therapy by increased dose of extrafine-particle ICS, relative to add-on LABA with ICS in combination (a) or separate (b) inhalers, as follows: Quadrant I: ICS step-up more costly and more effective (a trade-off); Quadrant II: ICS step-up more costly and less effective (thus, FDC ICS/LABA or separate ICS + LABA dominant); Quadrant III: ICS step-up less costly and less effective (a trade-off); and Quadrant IV: ICS step-up less costly and more effective (ICS step-up dominant). $F D C$ fixed-dose combination, ICS inhaled corticosteroid, $L A B A$ long-acting beta ${ }_{2}$-agonist 
matching for the ICS step-up cohort versus the separate ICS + LABA cohort and for the FDC ICS/LABA cohort versus the separate ICS + LABA cohort was in 1:2 ratios because of a baseline imbalance in numbers of unmatched patients. Baseline characteristics of matched patients in comparisons 1 and 2 are in Table S3 in the supplementary material. Approximately $22 \%$ of patients in comparisons 1 and 2 were smokers, and approximately 18\% were ex-smokers (Table S3).

Full results for comparison 3 (FDC ICS/LABA versus separate ICS + LABA) are reported in Tables S4-S6 in the supplementary material.

In all matched cohorts uncontrolled asthma was associated with increased costs (Table S7).

\section{Comparison 1: Asthma Step-Up Therapy Using an Increased Dose of Extrafine-Particle ICS Versus Add-On} LABA by FDC ICS/LABA Inhaler

After matching, there were 3036 patients in the ICS step-up and the FDC ICS/LABA cohorts. Patients' mean (standard deviation) age was 43 (16) years, 60\% being women (Table S3 in the supplementary material).

The percentage of patients meeting the risk-domain asthma control measure increased from $65 \%$ at baseline to $75 \%$ in both cohorts during the outcome year. The complete effectiveness results for comparison 1 have been previously published [20].

During the outcome year, asthma-related resource use was similar in the two cohorts with the exception of expected differences related to study design, such as use of ICS and FDC ICS/LABA inhalers and a greater number of SABA inhalers used by the ICS step-up cohort (Table 1). The mean baseline-adjusted, asthma-related healthcare costs for patients in the ICS step-up cohort were significantly lower than those for patients in the FDC ICS/LABA cohort (mean, £203 vs. £327; Table 2). When adjusted mean costs were combined with the adjusted effectiveness results-using asthma control as the effectiveness measure-there was a $56 \%$ probability that stepping up to a higher dose of extrafine-particle ICS would be less costly but less effective (a trade-off) and a $44 \%$ probability that ICS step-up would be the preferred treatment strategy (less costly and more effective). The uncertainty around the point estimates is illustrated in the cost-effectiveness plane (Fig. 1a). The point estimate for the ICER was $£ 51,449$. The CEAC showed that for no additional cost (willingness to pay $=£ 0$ ) an increased dose of the extrafine-particle ICS was the cost-effective option, since a zero value for the willingness to pay implies that only the cost is important in the cost-effectiveness calculation (Fig. 2).

\section{Comparison 2: Asthma Step-Up Therapy Using an Increased Dose of Extrafine-Particle ICS Versus Add-On}

\section{LABA by Separate Inhaler}

After matching, there were 3232 patients in the ICS step-up cohort and 6464 patients in the separate ICS + LABA cohort. Baseline patient characteristics and asthma-related resource use were similar to those of comparison 1 (Table S3 in the supplementary material).

The percentage of patients meeting the risk-domain asthma control measure increased from $65 \%$ at baseline to $75 \%$ in the ICS step-up cohort and to $71 \%$ in the separate ICS + LABA cohort at outcome.

During the outcome year, most categories of asthma-related resource use and costs were significantly lower for the ICS step-up cohort 
Table 1 Mean asthma-related drug prescriptions and unadjusted costs during the outcome year for patients receiving a step-up in ICS dose versus add-on LABA by FDC ICS/LABA inhaler (comparison 1)

\begin{tabular}{|c|c|c|c|c|c|c|}
\hline \multirow[t]{2}{*}{ Asthma-related resource ${ }^{b}$} & \multicolumn{3}{|c|}{ Mean (SD) resource use } & \multicolumn{3}{|c|}{ Mean $(\mathrm{SD})$ resource cost, $£$} \\
\hline & $\begin{array}{l}\text { ICS dose } \\
\text { step-up } \\
(N=3036)\end{array}$ & $\begin{array}{l}\text { FDC ICS/ } \\
\text { LABA } \\
(N=3036)\end{array}$ & $P$ value ${ }^{a}$ & $\begin{array}{l}\text { ICS dose } \\
\text { step-up } \\
(N=3036)\end{array}$ & $\begin{array}{l}\text { FDC ICS/ } \\
\text { LABA } \\
(N=3036)\end{array}$ & $P$ value ${ }^{a}$ \\
\hline ICS inhalers & $5.7(4.1)$ & $0.8(2.3)$ & $<0.001$ & $92(68)$ & $8(24)$ & $<0.001$ \\
\hline FDC ICS-LABA inhalers & $0.9(3.2)$ & $8.8(7.3)$ & $<0.001$ & $34(135)$ & $245(198)$ & $<0.001$ \\
\hline Long-acting $\beta_{2}$-agonist inhalers & $0.8(22.4)$ & $0.2(4.6)$ & $<0.001$ & $11(51)$ & $3(29)$ & $<0.001$ \\
\hline Short-acting $\beta_{2}$-agonist inhalers & $7.1(7.7)$ & $5.4(7.1)$ & $<0.001$ & $27(58)$ & $22(55)$ & $<0.001$ \\
\hline $\begin{array}{l}\text { Leukotriene receptor antagonist } \\
\text { prescriptions }\end{array}$ & $0.2(1.1)$ & $0.2(1.2)$ & 0.11 & $6(41)$ & $7(40)$ & 0.28 \\
\hline Antibiotic prescriptions ${ }^{c}$ & $1.0(1.6)$ & $1.0(1.5)$ & 0.39 & $3(11)$ & $4(15)$ & 0.30 \\
\hline Oral corticosteroid prescriptions & $0.3(1.0)$ & $0.3(0.9)$ & 0.067 & $1(7)$ & $1(5)$ & 0.67 \\
\hline Total mean medication costs & - & - & - & $174(182)$ & $290(220)$ & $<0.001$ \\
\hline $\begin{array}{l}\text { Total mean medication costs, } \\
\text { excluding ICS }\end{array}$ & - & - & - & $49(92)$ & $37(77)$ & $<0.001$ \\
\hline $\begin{array}{l}\text { Primary care asthma } \\
\text { consultations }\end{array}$ & $0.9(1.3)$ & $0.9(1.3)$ & 0.12 & $32(47)$ & $34(46)$ & 0.12 \\
\hline $\begin{array}{l}\text { Total asthma-related } \\
\text { hospitalizations }\end{array}$ & $0.0(0.3)$ & $0.1(0.3)$ & 0.21 & $9(67)$ & $10(68)$ & 0.34 \\
\hline Asthma-related inpatient & $0.0(0.1)$ & $0.0(0.1)$ & 0.72 & $3(54)$ & $4(54)$ & 0.72 \\
\hline Asthma-related outpatient & $0.0(0.2)$ & $0.0(0.3)$ & 0.25 & $5(34)$ & $6(36)$ & 0.25 \\
\hline $\begin{array}{l}\text { Asthma-related emergency } \\
\text { department visit }\end{array}$ & $0.0(0.1)$ & $0.0(0.1)$ & 0.64 & $0.7(11)$ & $0.9(12)$ & 0.64 \\
\hline $\begin{array}{l}\text { Total asthma-related primary and } \\
\text { secondary care, including ICS } \\
\text { costs }\end{array}$ & - & - & - & $215(226)$ & $334(254)$ & $<0.001$ \\
\hline $\begin{array}{l}\text { Total asthma-related primary and } \\
\text { secondary care, excluding ICS } \\
\text { costs }\end{array}$ & - & - & - & $90(139)$ & $81(123)$ & $<0.001$ \\
\hline
\end{tabular}

Mean values are reported, despite substantially skewed distributions, because mean values can be multiplied by a target population to estimate total costs and thus are of most interest for policy makers and providers

FDC Fixed-dose combination, ICS Inhaled corticosteroid, $L A B A$ Long-acting $\beta_{2}$-agonist, $S D$ Standard deviation

${ }^{a}$ Conditional logistic regression

b Asthma-related includes all database events coded for asthma and lower respiratory tract infection

c Antibiotics prescribed with accompanying lower respiratory tract infection Read code 
Table 2 Incremental cost-effectiveness analysis: ICS step-up versus FDC ICS/LABA inhaler (comparison 1) and ICS step-up versus ICS + LABA in separate inhalers (comparison 2)

\begin{tabular}{|c|c|c|c|c|}
\hline & \multicolumn{2}{|l|}{ Comparison 1} & \multicolumn{2}{|l|}{ Comparison 2} \\
\hline & $\begin{array}{l}\text { ICS dose } \\
\text { step-up } \\
(N=3036)\end{array}$ & $\begin{array}{l}\text { FDC ICS/ } \\
\text { LABA } \\
(N=3036)\end{array}$ & $\begin{array}{l}\text { ICS dose } \\
\text { step-up } \\
(N=3232)\end{array}$ & $\begin{array}{l}\text { Separate } \\
\text { ICS + LABA } \\
(N=6464)\end{array}$ \\
\hline $\begin{array}{l}\text { Risk-domain asthma control, adjusted } \\
\text { OR ( } 95 \% \mathrm{CI})\end{array}$ & $0.99(0.88-1.12)^{\mathrm{a}}$ & 1.00 & $1.25(1.13-1.38)^{\mathrm{d}}$ & 1.00 \\
\hline $\begin{array}{l}\text { Risk-domain asthma control, adjusted } \\
\text { proportion }(95 \% \mathrm{CI})^{\mathrm{b}}\end{array}$ & $0.44(0.37-0.50)^{\mathrm{a}}$ & $\begin{array}{l}0.44 \\
\quad(0.37-0.51)^{\mathrm{a}}\end{array}$ & $0.61(0.59-0.63)^{\mathrm{d}}$ & $\begin{array}{l}0.56 \\
\quad(0.53-0.58)^{\mathrm{d}}\end{array}$ \\
\hline $\begin{array}{l}\text { Difference relative to add-on LABA } \\
(95 \% \mathrm{CI})^{\mathrm{b}}\end{array}$ & $\begin{array}{l}0.002(-0.033 \text { to } \\
0.026)\end{array}$ & & $0.06(0.03-0.08)$ & \\
\hline $\begin{array}{l}\text { Adjusted mean asthma-related } \\
\text { healthcare costs per patient per year } \\
(95 \% \mathrm{CI})^{\mathrm{b}, \mathrm{c}}\end{array}$ & $£ 203(£ 197-£ 210)$ & $\begin{array}{l}£ 327 \\
\quad(£ 319-£ 336)\end{array}$ & $£ 204(£ 197-£ 210)$ & $\begin{array}{l}£ 337 \\
\quad(£ 332-£ 344)\end{array}$ \\
\hline \multirow[t]{2}{*}{$\begin{array}{l}\text { Difference relative to add-on LABA } \\
(95 \% \mathrm{CI})^{\mathrm{b}}\end{array}$} & $\begin{array}{l}-£ 124(-£ 135 \text { to } \\
-£ 114)\end{array}$ & & $\begin{array}{l}-£ 134(-£ 142 \text { to } \\
-£ 125)\end{array}$ & \\
\hline & \multicolumn{2}{|c|}{$\begin{array}{l}\text { Trade-off: ICS step-up significantly less } \\
\text { costly but marginally less effective }\end{array}$} & \multicolumn{2}{|c|}{$\begin{array}{l}\text { ICS step-up dominant: less costly and } \\
\text { more effective than separate } \\
\text { ICS + LABA }\end{array}$} \\
\hline Cost-effectiveness ratio (ICER) & $£ 51,499$ & & & \\
\hline
\end{tabular}

Confidence intervals determined using bootstrapping methods with 1000 random samples

$C I$ confidence interval, $F D C$ fixed-dose combination, ICER incremental cost-effectiveness ratio, ICS Inhaled corticosteroid, $L A B A$ long-acting $\beta_{2}$-agonist, OR Odds ratio

${ }^{a}$ Adjusted for: smoking status (current smoker/ex-smoker/nonsmoker/not specified), outpatient department attendance for asthma/lower respiratory reasons, number of acute oral corticosteroid prescriptions, and oral thrush

${ }^{\mathrm{b}}$ Confidence intervals determined using bootstrapping methods with 1000 random samples

${ }^{c}$ Adjusted for baseline asthma-related healthcare costs

d Adjusted for number of acute oral corticosteroid prescriptions

(Table 3), and the mean baseline-adjusted, asthma-related healthcare costs for patients in the ICS step-up cohort were significantly lower compared with those for patients remaining on the same ICS dose but adding a separate LABA (£204 vs. £337; Table 2). When costs were combined with the adjusted effectiveness results, there was a $100 \%$ probability that stepping up to a higher dose of extrafine-particle ICS would be less costly and more effective than adding a LABA by separate inhaler (Fig. 1b).

\section{DISCUSSION}

In this matched cohort cost-effectiveness study, UK patients stepping up to a higher dose of extrafine-particle ICS had significantly lower baseline-adjusted mean asthma-related healthcare costs compared with patients stepping up to an FDC ICS/LABA inhaler (mean difference of $£ 124$ per annum) during one outcome year. When these costs were combined with the adjusted effectiveness results, there was a $56 \%$ probability that 


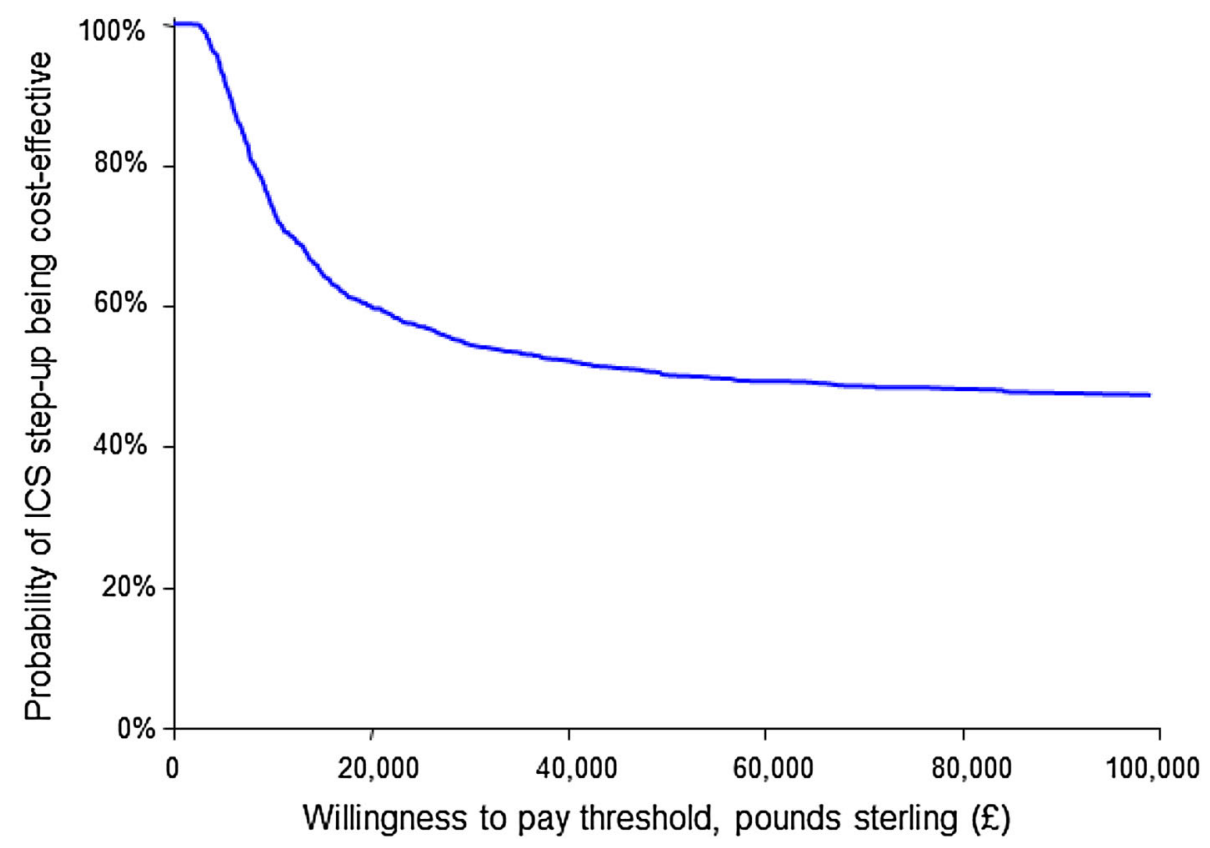

Fig. 2 Cost-effectiveness acceptability curve for an increased dose of extrafine-particle ICS (ICS step-up) relative to add-on LABA in a fixed-dose combination inhaler with ICS (ICS/LABA combination): Probability of

stepping up to a higher dose ICS would be less costly but less effective (a trade-off); a point estimate for the ICER, the monetary value of the intangible benefit to patients or society beyond the cost to achieve an additional controlled patient using an FDC ICS/LABA inhaler, was $£ 51,449$, reflecting the significantly higher costs of FDC therapy and the non-significant difference in effectiveness between treatments. There was a $44 \%$ probability that stepping up to a higher dose of extrafine-particle ICS would be the preferred treatment strategy (less costly and more effective). In our second comparison, ICS step-up was the preferred treatment strategy compared with adding LABA via separate inhaler: there was a $100 \%$ probability that stepping up to a higher dose of extrafine-particle ICS would be less costly and more effective. Of the two add-on LABA alternatives (comparison 3, reported in the
ICS step-up being cost-effective from the UK NHS perspective, adjusted results. ICS Inhaled corticosteroid, $L A B A$ Long-acting beta ${ }_{2}$-agonist, UK NHS United Kingdom National Health Service

supplementary material) prescribing an FDC ICS/LABA inhaler was more costly but also more effective (with 100\% probability) than prescribing a separate add-on LABA inhaler.

This study compared asthma-related direct costs for different step-up strategies in a primary care setting, which is where most patients with asthma receive treatment in the UK, as in many countries $[39,40]$. There are only a few studies that have examined real-life comparative costs for asthma step-up therapy [41, 42]. For patients with recent exacerbation or frequent SABA use identified in a recent retrospective cohort study conducted using a large US health insurance dataset, Hagiwara and coworkers [41] found that fluticasone/salmeterol combination was more effective in decreasing exacerbations and SABA use but more expensive than ICS dose step-up with fluticasone. In a broad United States (US) asthma population studied in 
Table 3 Mean asthma-related drug prescriptions and unadjusted costs during the outcome year for patients receiving a step-up in ICS dose versus add-on LABA by separate inhaler + ICS (comparison 2)

\begin{tabular}{|c|c|c|c|c|c|c|}
\hline \multirow[t]{2}{*}{ Asthma-related resource ${ }^{c}$} & \multicolumn{3}{|c|}{ Mean (SD) resource use } & \multicolumn{3}{|c|}{ Mean $(\mathrm{SD})$ resource cost, $€$} \\
\hline & $\begin{array}{l}\text { ICS dose } \\
\text { step-up } \\
(N=3232)\end{array}$ & $\begin{array}{l}\text { Separate } \\
\text { ICS + LABA } \\
(N=6464)\end{array}$ & $P$ value ${ }^{a}$ & $\begin{array}{l}\text { ICS dose } \\
\text { step-up } \\
(N=3232)\end{array}$ & $\begin{array}{l}\text { Separate } \\
\text { ICS + LABA } \\
(N=6464)\end{array}$ & $P$ value ${ }^{a}$ \\
\hline ICS inhalers & $5.7(4.1)$ & $4.5(4.1)$ & $<0.001$ & $91(69)$ & $43(50)$ & $<0.001$ \\
\hline $\begin{array}{l}\text { Fixed-dose combination ICS/ } \\
\text { LABA inhalers }\end{array}$ & $0.9(3.2)$ & $1.6(4.5)$ & $<0.001$ & $34(134)$ & $57(168)$ & $<0.001$ \\
\hline Long-acting $\beta_{2}$-agonist inhalers & $0.8(21.8)$ & $5.8(24.7)$ & $<0.001$ & $11(52)$ & $155(150)$ & $<0.001$ \\
\hline Short-acting $\beta_{2}$-agonist inhalers & $7.1(8.0)$ & $6.5(7.7)$ & $<0.001$ & $27(58)$ & $25(51)$ & 0.072 \\
\hline $\begin{array}{l}\text { Leukotriene receptor antagonist } \\
\text { prescriptions }\end{array}$ & $0.2(1.0)$ & $0.2(1.2)$ & 0.26 & $6(42)$ & $6(40)$ & 0.85 \\
\hline Antibiotic prescriptions & $1.0(1.7)$ & $1.0(1.9)$ & 0.54 & $3(11)$ & $4(15)$ & 0.33 \\
\hline Oral corticosteroid prescriptions & $0.4(1.0)$ & $0.4(1.1)$ & $<0.001$ & $1(6)$ & $2(6)$ & $<0.001$ \\
\hline Total mean medication costs & - & - & - & $174(182)$ & $292(242)$ & $<0.001$ \\
\hline $\begin{array}{l}\text { Total mean medication costs, } \\
\text { excluding ICS }\end{array}$ & - & - & - & $49(92)$ & $192(173)$ & $<0.001$ \\
\hline $\begin{array}{l}\text { Primary care asthma } \\
\text { consultations }\end{array}$ & $0.9(1.3)$ & $1.1(1.4)$ & $<0.001$ & $33(48)$ & $41(52)$ & $<0.001$ \\
\hline $\begin{array}{l}\text { Total asthma-related } \\
\text { hospitalizations }\end{array}$ & $0.0(0.3)$ & $0.1(0.3)$ & 0.050 & $8(62)$ & $13(93)$ & 0.006 \\
\hline Asthma-related inpatient & $0.0(0.1)$ & $0.0(0.1)$ & 0.011 & $3(49)$ & $7(80)$ & 0.011 \\
\hline Asthma-related outpatient & $0.0(0.2)$ & $0.0(0.3)$ & 0.16 & $4(32)$ & $5(36)$ & 0.16 \\
\hline $\begin{array}{l}\text { Asthma-related emergency } \\
\text { department visit }\end{array}$ & $0.0(0.1)$ & $0.0(0.1)$ & 0.94 & $1(13)$ & $1(13)$ & 0.94 \\
\hline $\begin{array}{l}\text { Total asthma-related primary } \\
\text { and secondary care, including } \\
\text { ICS costs }\end{array}$ & - & - & - & $215(224)$ & $345(283)$ & $<0.001$ \\
\hline $\begin{array}{l}\text { Total asthma-related primary } \\
\text { and secondary care, excluding } \\
\text { ICS costs }\end{array}$ & - & - & - & $90(136)$ & $246(209)$ & $<0.001$ \\
\hline
\end{tabular}

Mean values are reported, despite substantially skewed distributions, because mean values can be multiplied by a target population to estimate total costs and thus are of most interest for policy makers and providers

$I C S$ inhaled corticosteroid, $L A B A$ long-acting $\beta_{2}$-agonist, $S D$ standard deviation

${ }^{a}$ Conditional logistic regression

b Asthma-related includes all database events coded for asthma and lower respiratory tract infection 
2002-2004, direct medical costs and asthma-related healthcare resource utilization were lower with ICS monotherapy as compared with FDC ICS/LABA therapy (cost-effectiveness was not reported) [42]. Other published cost-effectiveness analyses based on short-term RCT results report that FDC ICS/LABA therapy, while more expensive, usually meets benchmarks for cost-effectiveness [12-15].

Administering LABA by separate inhaler was not a cost-effective alternative in this study as compared with either ICS step-up or an FDC ICS/LABA inhaler. Similar findings were reported in prior RCTs [13]. In addition, administering LABA by separate inhaler is discouraged by asthma guidelines because LABA monotherapy (without ICS) has been associated with serious adverse asthma-related outcomes, including deaths, seen in early trials $[8,43]$. Instead, an FDC ICS/LABA inhaler is recommended to ensure that patients take concomitant ICS.

A strength of this study is the large patient population, with over 38,000 patients studied, and the minimal exclusion criteria designed to capture data for a broad general population treated for asthma in primary care. Treatment cohorts were matched according to several criteria reflecting baseline asthma severity and control. Effectiveness measures were adjusted for residual confounding. Nonetheless, we cannot exclude the possibility of unrecognized confounders, including measures that were not available for all patients, such as smoking status and socioeconomic status, or that were not present in the database, such as pack-years of smoking. We were limited to the available database information in developing our asthma control measure; however, it would have been of interest to also include patient-reported outcomes (including actual SABA use rather than inhalers prescribed) in our definition of asthma control, as $58-65 \%$ of each cohort were evaluated as controlled at baseline according to our measure. Nevertheless, all patients were prescribed a step-up in therapy at the index date, which suggests that they or their physician did not consider their asthma to be well-controlled.

We had no way to measure patient satisfaction with therapy; however, we inferred from the treatment change data in the companion effectiveness study that there were no major differences in patient satisfaction between ICS step-up and FDC ICS/LABA step-up as the same proportions of patients in the two cohorts changed therapy during the outcome year [20]. Nevertheless, the issue of patient satisfaction with step-up therapy would be an important outcome to explore in a pragmatic trial. Patient satisfaction and patient preferences are potentially important influences on patient adherence to therapy and hence must be factored into clinical prescribing decisions $[3,8]$. In addition, ICS doses should be tailored to the level of symptom control, lung function, and exacerbations, all relating to the degree of airways inflammation.

Double counting may have occurred in this analysis because the numerator included the difference in costs of asthma-related resource utilization and the asthma control effectiveness measure was a function of asthma-related events. Therefore, the cost estimates in the ICERs are interpreted as the willingness-to-pay over and above the cost to achieve an additional controlled patient. In other words, ICERs in this case represent the monetary value of the intangible benefit to patients or society beyond the cost to achieve an additional controlled patient over the outcome period [44].

The ICER of $£ 51,000$ for prescribing FDC ICS/ LABA therapy instead of ICS dose step-up was 
calculated using a composite database measure of risk-domain asthma control as the effectiveness measure. The more common calculation of ICER per additional quality-adjusted life-year (QALY), as used by the UK National Institute for Health and Care Excellence (NICE), was not possible from the available data. The cost-effectiveness threshold used by NICE is $£ 20,000$ to $£ 30,000$ for cost per QALY [45]. Because of our approach in using an intermediate effectiveness measure instead of a composite measure such as QALYs, we cannot make comparisons to results from cost-utility analyses for unrelated interventions or treatments. To increase comparability with unrelated interventions, future pragmatic trials should address treatment preferences to calculate both within-trial cost-per-QALY ratios and projected lifetime cost-per-QALY ratios using assumptions around asthma-specific mortality.

In addition, our study findings apply primarily to the UK healthcare system, and further investigations are needed from other perspectives, using different effectiveness measures, and in the setting of other healthcare systems, as costs are highly variable among countries. Moreover, prescribing preferences can vary according to location. Assessment of indirect costs is needed as well.

We chose to investigate extrafine-particle beclomethasone, with aerosol particle MMAD of $1.1 \mu \mathrm{m}$, for the ICS step-up therapy because of its good distribution to the small airways, often a site of persistent inflammation in patients with poorly controlled asthma [18, 46-48]. In a prior, similarly designed cost-effectiveness study of patients initiating ICS therapy for asthma, we found that initiating with an extrafine ICS as compared with standard fine-particle ICS (MMAD of 2.4-3.2 $\mu \mathrm{m}$, depending on formulation) $\mathrm{had} \geq 84 \%$ probability of being the preferred treatment, i.e., less costly and more effective, in both the UK and the USA [49]. Further observational studies are needed to compare the cost-effectiveness of step-up regimens with other extrafine-particle ICS, such as ciclesonide (MMAD of $1.0 \mu \mathrm{m})$, and the standard fine-particle ICS, such as fluticasone (MMAD, 2.4-5.4 $\mu \mathrm{m}) \quad$ and budesonide (MMAD, $\sim 4.0 \mu \mathrm{m})$.

\section{CONCLUSIONS}

We found that, among available step-up therapy alternatives for adults with persistent asthma on ICS monotherapy cared for in UK clinical practice, adding a LABA via separate inhaler is the least cost-effective option. Increasing extrafine-particle ICS dose is significantly less costly from the payer perspective and marginally (non-significantly) less effective than FDC ICS/LABA therapy containing standard fine-particle ICS. From the UK NHS payer perspective, the cost to achieve an additional controlled patient using an FDC ICS/LABA combination rather than ICS dose step-up using extrafine particles is very high $(£ 51,449)$. In countries with strong economic constraints, this may lead to questioning the recommendation of FDC ICS/LABA as first choice when treatment step-up is required, especially when considering that extrafine-particle ICS dose step-up has a $44 \%$ probability of being the cost-effective option relative to FDC ICS/LABA. These findings warrant further investigation in other healthcare systems and with a range of ICS in pragmatic trials and observational studies. 


\section{ACKNOWLEDGMENTS}

The analyses were funded by an unrestricted grant from Teva Pharmaceuticals Limited of Petach Tikva, Israel. Access to data from the Optimum Patient Care Research Database was co-funded by Research in Real-Life Ltd (RiRL), Cambridge, UK. All named authors meet the International Committee of Medical Journal Editors (ICMJE) criteria for authorship for this manuscript, take responsibility for the integrity of the work as a whole, and have given final approval to the version to be published. The authors thank Julie von Ziegenweidt for assistance with data extraction.

Disclosures. In the past 3 years, Nicolas Roche received (1) fees for speaking, organizing education, participation in advisory boards or consulting from $3 \mathrm{M}$, Aerocrine, Almirall, AstraZeneca, Boehringer Ingelheim, Chiesi, Cipla, GlaxoSmithKline, MSD-Chibret, Mundipharma, Novartis, Pfizer, Sandoz, Sanofi, Stallergenes, Takeda, Teva; (2) research grants from Novartis, Boehringer Ingelheim and Pfizer. Gene Colice has acted as a speaker/consultant/ Advisory Board member for Teva, MedImmune, Mylan, Boehringer Ingelheim. Elliot Israel reports having received over the past 3 years consulting fees from AstraZeneca, Cowen \& Co, Novartis, Philips Respironics, Regeneron Pharmaceuticals, and TEVA Specialty Pharmaceuticals; fees for expert testimony from Campbell, Campbell, Edwards \& Conroy, Crammer, Bishop \& O'Brien, Fox Rothschild, and Ryan Ryan Deluca LLP; travel grant support from Research in Real Life (RiRL), TEVA Specialty Pharmaceuticals; Royalties from UpToDate; Deputy Editor fees from the American Thoracic Society; DSMB Member for Novartis with no compensation; and having grant support paid to his Institution from Genentech and the NIH. Richard J. Martin has done consultancy work and/or received travel support and/or honoraria for attendance at advisory boards for Teva; received research grants from MedImmune and the NHLBI; received royalties from UpToDate. Paul M. Dorinsky was a full-time Teva employee at the time this project was initiated. He was not employed by Teva when the project was completed or during manuscript preparation. The University of Groningen has received money for Dirkje S. Postma regarding an unrestricted educational grant for research from AstraZeneca. Travel to ERS and/or ATS has been partially funded by AstraZeneca, Chiesi, GSK, Takeda. Fees for consultancies were given to the University of Groningen by AstraZeneca, Boehringer Ingelheim, Chiesi, GSK, Takeda and TEVA. Travel and lectures in China paid by Chiesi. Theresa W. Guilbert reports personal fees from American Board of Pediatrics; Pediatric Pulmonary Subboard, grants and personal fees from Teva, personal fees from GSK and Merck, personal fees from Regeneron Pharmaceuticals, grants from CDC, grants from DHHS, grants from NIH, grants from UW-Madison Medical and Education Research Committee, grants from Abbott Laboratories, grants from Array Biopharma, grants from Mylan, grants from Forest Research Institute, grants from $F$. Hoffman-LaRoche, grants from Medimmune, grants from KaloBios Pharmaceuticals, grants from Vertex Pharmaceuticals, grants from Roxane Laboratories and CompleWare Corporation, grants from CF Foundation Therapeutics, grants from Roche/Genentech, and royalties from UpToDate. Jonathan Grigg received honoraria from Novartis as a member of an advisory board for an asthma medication and received travel expenses and hotel accommodation from Research in Real Life Ltd, 
to attend meetings related to the study. Willem M.C. van Aalderen is a member of the Medical Advisory Board of AstraZeneca. Francesca Barion, Victoria Thomas, Anne Burden, and R. Brett McQueen were employees of RiRL, which conducted this study and which has conducted paid research in respiratory disease on behalf of the following other organizations in the past 5 years: Aerocrine, AKL Ltd, Almirall, AstraZeneca, Boehringer Ingelheim, Chiesi, GlaxoSmithKline, Meda, Mundipharma, Napp, Novartis, Orion, Takeda, Teva, and Zentiva. Elizabeth V. Hillyer is a consultant to RiRL and has received payment for writing and editorial support to Merck. David B. Price has Board Membership with Aerocrine, Almirall, Amgen, AstraZeneca, Boehringer Ingelheim, Chiesi, Meda, Mundipharma, Napp, Novartis, and Teva. Consultancy: Almirall, Amgen, AstraZeneca, Boehringer Ingelheim, Chiesi, GlaxoSmithKline, Meda, Mundipharma, Napp, Novartis, Pfizer, Teva, and Zentiva; Grants/ Grants Pending with UK National Health Service, British Lung Foundation, Aerocrine, AstraZeneca, Boehringer Ingelheim, Chiesi, Eli Lilly, GlaxoSmithKline, Meda, Merck, Mundipharma, Novartis, Orion, Pfizer, Respiratory Effectiveness Group, Takeda, Teva, and Zentiva; Payments for lectures/speaking: Almirall, AstraZeneca, Boehringer Ingelheim, Chiesi, Cipla, GlaxoSmithKline, Kyorin, Meda, Merck, Mundipharma, Novartis, Pfizer, SkyePharma, Takeda, and Teva; Payment for manuscript preparation: Mundipharma and Teva; Patents (planned, pending or issued): AKL Ltd.; Payment for the development of educational materials: GlaxoSmithKline, Novartis; Stock/Stock options: Shares in AKL Ltd which produces phytopharmaceuticals and owns $80 \%$ of Research in Real Life Ltd and its subsidiary social enterprise Optimum Patient Care; received Payment for travel/ accommodations/meeting expenses from Aerocrine, Boehringer Ingelheim, Mundipharma, Napp, Novartis, and Teva; Funding for patient enrollment or completion of research: Almirral, Chiesi, Teva, and Zentiva; Peer reviewer for grant committees: Medical Research Council (2014), Efficacy and Mechanism Evaluation programme (2012), HTA (2014); and Received unrestricted funding for investigator-initiated studies from Aerocrine, AKL Ltd, Almirall, Boehringer Ingelheim, Chiesi, Meda, Mundipharma, Napp, Novartis, Orion, Takeda, Teva, and Zentiva.

Compliance with Ethics Guidelines. This was a retrospective study utilizing anonymized patient data, for which formal consent is not required.

Open Access. This article is distributed under the terms of the Creative Commons Attribution-NonCommercial 4.0 International License (http://creativecommons.org/licenses/ by-nc/4.0/), which permits any noncommercial use, distribution, and reproduction in any medium, provided you give appropriate credit to the original author(s) and the source, provide a link to the Creative Commons license, and indicate if changes were made.

\section{REFERENCES}

1. The Global Asthma Network. The global asthma report 2014. Auckland, New Zealand. www. globalasthmareport.org. Accessed February 16, 2016.

2. Asthma UK. Asthma facts and FAQs. 2015. http:// www.asthma.org.uk/asthma-facts-and-statistics. Accessed February 16, 2016.

3. Global Initiative for Asthma. Global strategy for asthma management and prevention, updated April 2015. www.ginasthma.org. Accessed February 16, 2016. 
4. Bahadori K, Doyle-Waters MM, Marra C, et al. Economic burden of asthma: a systematic review. BMC Pulm Med. 2009;9:24.

5. Cisternas MG, Blanc PD, Yen $\mathrm{IH}$, et al. A comprehensive study of the direct and indirect costs of adult asthma. J Allergy Clin Immunol. 2003;111:1212-8.

6. Gold LS, Thompson P, Salvi S, et al. Level of asthma control and health care utilization in Asia-Pacific countries. Respir Med. 2014;108:271-7.

7. Doz M, Chouaid C, Com-Ruelle L, et al. The association between asthma control, health care costs, and quality of life in France and Spain. BMC Pulm Med. 2013;13:15.

8. British Thoracic Society, Scottish Intercollegiate Guidelines Network. British guideline on the management of asthma. A national clinical guideline. Revised 2014. http://www.sign.ac.uk/ guidelines/fulltext/141/. Accessed February 16, 2016.

9. Travers J, Marsh S, Williams M, et al. External validity of randomised controlled trials in asthma: to whom do the results of the trials apply? Thorax. 2007;62:219-23.

10. Price D, Bateman ED, Chisholm A, et al. Complementing the randomized controlled trial evidence base. Evolution not revolution. Ann Am Thorac Soc. 2014;11(Suppl 2):S92-8.

11. Roche N, Reddel HK, Agusti A, et al. Integrating real-life studies in the global therapeutic research framework. Lancet Respir Med. 2013;1:e29-30.

12. Shepherd J, Rogers G, Anderson R, et al. Systematic review and economic analysis of the comparative effectiveness of different inhaled corticosteroids and their usage with long-acting beta 2 agonists for the treatment of chronic asthma in adults and children aged 12 years and over. Health Technol Assess. 2008;12:1-360.

13. Bahadori K, Quon BS, Doyle-Waters MM, et al. A systematic review of economic evaluations of therapy in asthma. J Asthma Allergy. 2010;3:33-42.

14. Shih YC, Mauskopf J, Borker R. A cost-effectiveness analysis of first-line controller therapies for persistent asthma. Pharmacoeconomics. 2007;25:577-90.

15. Doull I, Price D, Thomas M, et al. Cost-effectiveness of salmeterol xinafoate/fluticasone propionate combination inhaler in chronic asthma. Curr Med Res Opin. 2007;23:1147-59.
16. Jarvinen TL, Sievanen H, Kannus P, et al. The true cost of pharmacological disease prevention. BMJ. 2011;342:d2175.

17. Garrison LP Jr, Neumann PJ, Erickson P, et al. Using real-world data for coverage and payment decisions: the ISPOR real-world data task force report. Value Health. 2007;10:326-35.

18. van den Berge $\mathrm{M}$, ten Hacken $\mathrm{NH}$, van der Wiel $\mathrm{E}$, et al. Treatment of the bronchial tree from beginning to end: targeting small airway inflammation in asthma. Allergy. 2013;68:16-26.

19. Lipworth B. Targeting the small airways asthma phenotype: if we can reach it, should we treat it? Ann Allergy Asthma Immunol. 2013;110:233-9.

20. Israel E, Roche N, Martin RJ, et al. Increased dose of inhaled corticosteroid vs. add-on long-acting beta-agonist for step-up therapy in asthma. Ann Am Thorac Soc. 2015;12:798-806.

21. Clinical Practice Research Datalink. http://www. cprd.com/home/. Accessed February 16, 2016.

22. Walley T, Mantgani A. The UK General Practice Research Database. Lancet. 1997;350:1097-9.

23. Jick SS, Kaye JA, Vasilakis-Scaramozza C, et al. Validity of the General Practice Research Database. Pharmacotherapy. 2003;23:686-9.

24. Optimum Patient Care Research Database (OPCRD). http://optimumpatientcare.org/opcrd/. Accessed February 16, 2016.

25. Roche N, Reddel H, Martin R, et al. Quality standards for real-world research. Focus on observational database studies of comparative effectiveness. Ann Am Thorac Soc. 2014;11(Suppl 2):S99-104.

26. Personal Social Services Research Unit. Unit costs of health and social care 2007. 2007. http://www. pssru.ac.uk/project-pages/unit-costs/2007/index. php. Accessed February 16, 2016.

27. Department of Health. NHS reference costs 2010-11. Crown. 2011. http://www.dh.gov.uk/en/ Publicationsandstatistics/Publications/Publications PolicyAndGuidance/DH_131140. Accessed February 16, 2016.

28. Prescription Services, National Health Service (NHS) Business Services Authority. Dictionary of medicines and devices $(\mathrm{dm}+\mathrm{d})$ database. Prescription Services. 2012. http://dmd.medicines. org.uk. Accessed February 16, 2016. 
29. Colice G, Martin RJ, Israel E, et al. Asthma outcomes and costs of therapy with extrafine beclomethasone and fluticasone. J Allergy Clin Immunol. 2013;132:45-54.

30. Barnes N, Price D, Colice G, et al. Asthma control with extrafine-particle hydrofluoroalkane-beclometasone vs. large-particle chlorofluorocarbon-beclometasone: a real-world observational study. Clin Exp Allergy. 2011;41:1521-32.

31. Price D, Martin RJ, Barnes N, et al. Prescribing practices and asthma control with hydrofluoroalkane-beclomethasone and fluticasone: a real-world observational study. J Allergy Clin Immunol. 2010;126(511-8):e1-10.

32. Reddel HK, Taylor DR, Bateman ED, et al. An official American Thoracic Society/European Respiratory Society statement: asthma control and exacerbations: standardizing endpoints for clinical asthma trials and clinical practice. Am J Respir Crit Care Med. 2009;180:59-99.

33. Akinbami LJ, Sullivan SD, Campbell JD, et al. Asthma outcomes: healthcare utilization and costs. J Allergy Clin Immunol. 2012;129(3 Suppl):S49-64.

34. Vanderweil SG, Tsai CL, Pelletier AJ, et al. Inappropriate use of antibiotics for acute asthma in United States emergency departments. Acad Emerg Med. 2008;15:736-43.

35. Briggs AH, Wonderling DE, Mooney CZ. Pulling cost-effectiveness analysis up by its bootstraps: a non-parametric approach to confidence interval estimation. Health Econ. 1997;6:327-40.

36. O'Brien BJ, Briggs AH. Analysis of uncertainty in health care cost-effectiveness studies: an introduction to statistical issues and methods. Stat Methods Med Res. 2002;11:455-68.

37. van Hout BA, Al MJ, Gordon GS, et al. Costs, effects and C/E-ratios alongside a clinical trial. Health Econ. 1994;3:309-19.

38. Lothgren M, Zethraeus N. Definition, interpretation and calculation of cost-effectiveness acceptability curves. Health Econ. 2000;9:623-30.
39. Roland M, Guthrie B, Thome DC. Primary medical care in the United Kingdom. J Am Board Fam Med. 2012;25(Suppl 1):S6-11.

40. Campbell SM, Reeves D, Kontopantelis E, et al. Effects of pay for performance on the quality of primary care in England. $\mathrm{N}$ Engl $\mathrm{J}$ Med. 2009;361:368-78.

41. Hagiwara M, Delea TE, Stanford RH. Health-care utilization and costs with fluticasone propionate and fluticasone propionate/salmeterol in asthma patients at risk for exacerbations. Allergy Asthma Proc. 2014;35:54-62.

42. Zeiger RS, Hay JW, Contreras R, et al. Asthma costs and utilization in a managed care organization. J Allergy Clin Immunol. 2008;121:885-92.

43. Chowdhury BA, Dal Pan G. The FDA and safe use of long-acting beta-agonists in the treatment of asthma. N Engl J Med. 2010;362:1169-71.

44. Mullins CD. Double counting and the reporting of cost per event avoided. Clin Ther. 2006;28:602-3.

45. Raftery JP. NICE's cost-effectiveness range: should it be lowered? Pharmacoeconomics. 2014;32:613-5.

46. Leach CL, Davidson PJ, Hasselquist BE, et al. Lung deposition of hydrofluoroalkane-134a beclomethasone is greater than that of chlorofluorocarbon fluticasone and chlorofluorocarbon beclomethasone: a cross-over study in healthy volunteers. Chest. 2002;122:510-6.

47. Anderson WJ, Zajda E, Lipworth BJ. Are we overlooking persistent small airways dysfunction in community-managed asthma? Ann Allergy Asthma Immunol. 2012;109(185-9):e2.

48. Farah CS, King GG, Brown NJ, et al. The role of the small airways in the clinical expression of asthma in adults. J Allergy Clin Immunol. 2012;129:381-7.

49. Martin RJ, Price D, Roche N, et al. Cost-effectiveness of initiating extrafine- or standard size-particle inhaled corticosteroid for asthma in two health-care systems: a retrospective matched cohort study. NPJ Prim Care Respir Med. 2014;24:14081. 